\title{
Calcium electroporation in three cell lines: a comparison of bleomycin and calcium, calcium compounds, and pulsing conditions
}

\author{
Stine Krog Frandsen ${ }^{\mathrm{a}}$, Hanne Gissel ${ }^{\mathrm{b}}$, Pernille Hojman ${ }^{\mathrm{c}}$, Jens Eriksen ${ }^{\mathrm{a}, \mathrm{d}}$, Julie Gehl ${ }^{\mathrm{a}, *}$ \\ a Center for Experimental Drug and Gene Electrotransfer, Department of Oncology, Copenhagen University Hospital Herlev, Herlev Ringvej 75, 2730 Herlev, Denmark \\ b Institute of Biomedicine, Aarhus University, Building 1160, Ole Worms Allé 4, 8000 Aarhus C, Denmark \\ c Centre of Inflammation and Metabolism, Department of Infectious Diseases, Copenhagen University Hospital, Blegdamsvej 9, 2100 Copenhagen, Denmark \\ d Department of Pathology, Naestved Sygehus, Ringstedgade 61, 4700 Naestved, Denmark
}

\section{A R T I C L E I N F O}

\section{Article history:}

Received 13 September 2013

Received in revised form 15 November 2013

Accepted 9 December 2013

Available online 14 December 2013

\section{Keywords:}

Calcium electroporation

Electrochemotherapy

Bleomycin

In vitro

Cancer

\begin{abstract}
A B S T R A C T
Background: Electroporation with calcium (calcium electroporation) can induce ATP depletion-associated cellular death. In the clinical setting, the cytotoxic drug bleomycin is currently used with electroporation (electrochemotherapy) for palliative treatment of tumors. Calcium electroporation offers several advantages over standard treatment options: calcium is inexpensive and may readily be applied without special precautions, as is the case with cytostatic drugs. Therefore, details on the use of calcium electroporation are essential for carrying out clinical trials comparing calcium electroporation and electrochemotherapy.

Methods: The effects of calcium electroporation and bleomycin electroporation (alone or in combination) were compared in three different cell lines (DC-3F, transformed Chinese hamster lung fibroblast; K-562, human leukemia; and murine Lewis Lung Carcinoma). Furthermore, the effects of electrical pulsing parameters and calcium compound on treatment efficacy were determined.

Results: Electroporation with either calcium or bleomycin significantly reduced cell survival $(\mathrm{p}<0.0001)$, without evidence of a synergistic effect. Cellular death following calcium or bleomycin treatment occurred at similar applied voltages, suggesting that similar parameters should be applied. At equimolar concentrations, calcium chloride and calcium glubionate resulted in comparable decreases in cell viability.

Conclusions: Calcium electroporation and bleomycin electroporation significantly reduce cell survival at similar applied voltage parameters. The effect of calcium electroporation is independent of calcium compound. General significance: This study strongly supports the use of calcium electroporation as a potential cancer therapy and the results may aid in future clinical trials.
\end{abstract}

(c) 2013 Published by Elsevier B.V.

\section{Introduction}

Electroporation, where short, high voltage electric pulses induce permeabilisation of the cell membrane, is used in combination with chemotherapeutic drugs (electrochemotherapy) for local treatment of malignant tumors both in the clinical management of cancer [1-11] and in veterinarian medicine [12-14]. Over the years several novel agents have been applied in combination with electroporation [15-19]. Recently, it was shown that calcium, in combination with electroporation (calcium electroporation), could eradicate tumors by inducing cellular death and tumor necrosis [20]. This finding suggests that calcium is a possible new agent for electroporation-based cancer therapy.

Abbreviations: ANOVA, Analysis of Variance; MTT, 3-(4,5-Dimethylthiazol-2-yl)-2,5diphenyltetrazolium bromide

* Corresponding author at: Center for Experimental Drug and Gene Electrotransfer (C*EDGE), Department of Oncology, Copenhagen University Hospital Herlev, Herlev

Ringvej 75, 2730 Herlev, Denmark. Tel.: + 45 38682981; fax: + 4544533076.

E-mail address: Julie.Gehl@regionh.dk (J.Gehl).
Numerous existing anti-cancer therapies affect calcium signaling, supporting the idea of calcium pathways as a target in cancer treatment $[21,22]$. Calcium is a ubiquitous second messenger and depending on time, place, amplitude, frequency, and duration, it is involved in several cellular processes, including cell death. Accordingly, calcium is tightly regulated within cells [23-27]. In eukaryotic cells, the cytosolic concentration of free calcium is approximately $10^{-7} \mathrm{M}$, a concentration that is very low compared to the extracellular concentration of approximately $10^{-3} \mathrm{M}$. This suggests that even a small influx of calcium will lead to a dramatic increase in intracellular calcium concentration [28]. By electroporating cells or tumors in the presence of calcium, the intracellular calcium concentration increases greatly, resulting in energy depletion [20], likely caused by direct ATP loss, increased ATP expenditure due to activity of the $\mathrm{Ca}^{2+}$-ATPase and other ATPases, as well as loss of ATP production.

Calcium electroporation has shown great efficacy when using reversible electroporation parameters (microsecond pulses) [20]. Alternative electroporation methods, such as irreversible electroporation or nanosecond pulse electroporation, have yet to be tested with calcium. Irreversible electroporation has been tested as an anti-cancer treatment 
[29] and its efficacy might be increased when combined with calcium injection. Nanosecond pulse electroporation has been shown to cause a transient increase in the intracellular calcium concentration by influx of calcium from the extracellular space, as well as calcium release from the endoplasmic reticulum [30,31]. Therefore, nanosecond pulse electroporation, which also has been tested as an anti-cancer treatment [32,33], might be potentiated by addition of calcium injection.

In the field of gene therapy, calcium electroporation may have yet another interesting perspective. When using electroporation-based gene electrotransfer, a particular tissue area (e.g. muscle) is used as host tissue for a transgene, which may encode a therapeutic protein. This protein can be excreted to the bloodstream to exert a systemic effect [34-39]. Several clinical trials have tested gene therapy in both humans [38] and animals [40-42]. As a method to terminate transgene expression, due to unexpected side effects or other reasons, calcium electroporation may be applied to the relevant tissues [43].

Before calcium electroporation can be implemented in the clinical setting, several things must be investigated: 1 ) the efficacy of calcium electroporation must be directly compared to bleomycin-based electrochemotherapy. Furthermore, a possible synergy between the effects of calcium and bleomycin must be explored. 2) Electroporation depends on electrical field induced membrane permeabilisation. As calcium ions are significantly smaller than bleomycin molecules, it would be of interest to test whether different electroporation parameters should be applied. Calcium electroporation has previously been tested using identical electric field strengths as those applied in electrochemotherapy [20,43]. 3) Calcium intended for injection is commercially available and routinely used at most hospitals. Two different calcium compounds, namely calcium chloride and calcium glubionate, are approved for clinical use. We therefore aim to compare both compounds in calcium electroporation.

\section{Material and methods}

\subsection{Cell culturing}

Three cell lines were used for the experiments, DC-3F, a transformed Chinese hamster lung fibroblast cell line; K-562, a human leukemia cell line; and Lewis Lung Carcinoma, a murine lung carcinoma cell line. The cell lines were mycoplasma-negative, tested using MycoAlert Mycoplasma Detection Kit (Lonza) prior to experiments. Cells were maintained in RPMI 1640 culture medium (Gibco, Invitrogen) with $10 \%$ fetal calf serum (Gibco, Invitrogen), penicillin, and streptomycin at $37{ }^{\circ} \mathrm{C}$ and $5 \% \mathrm{CO}_{2}$.

\subsection{Electroporation protocol}

Following harvesting, cells were diluted in HEPES buffer (10 mM HEPES (Lonza), $250 \mathrm{mM}$ sucrose and $1 \mathrm{mM} \mathrm{MgCl} 2$ in sterile water). This buffer not containing phosphate was used since calcium and
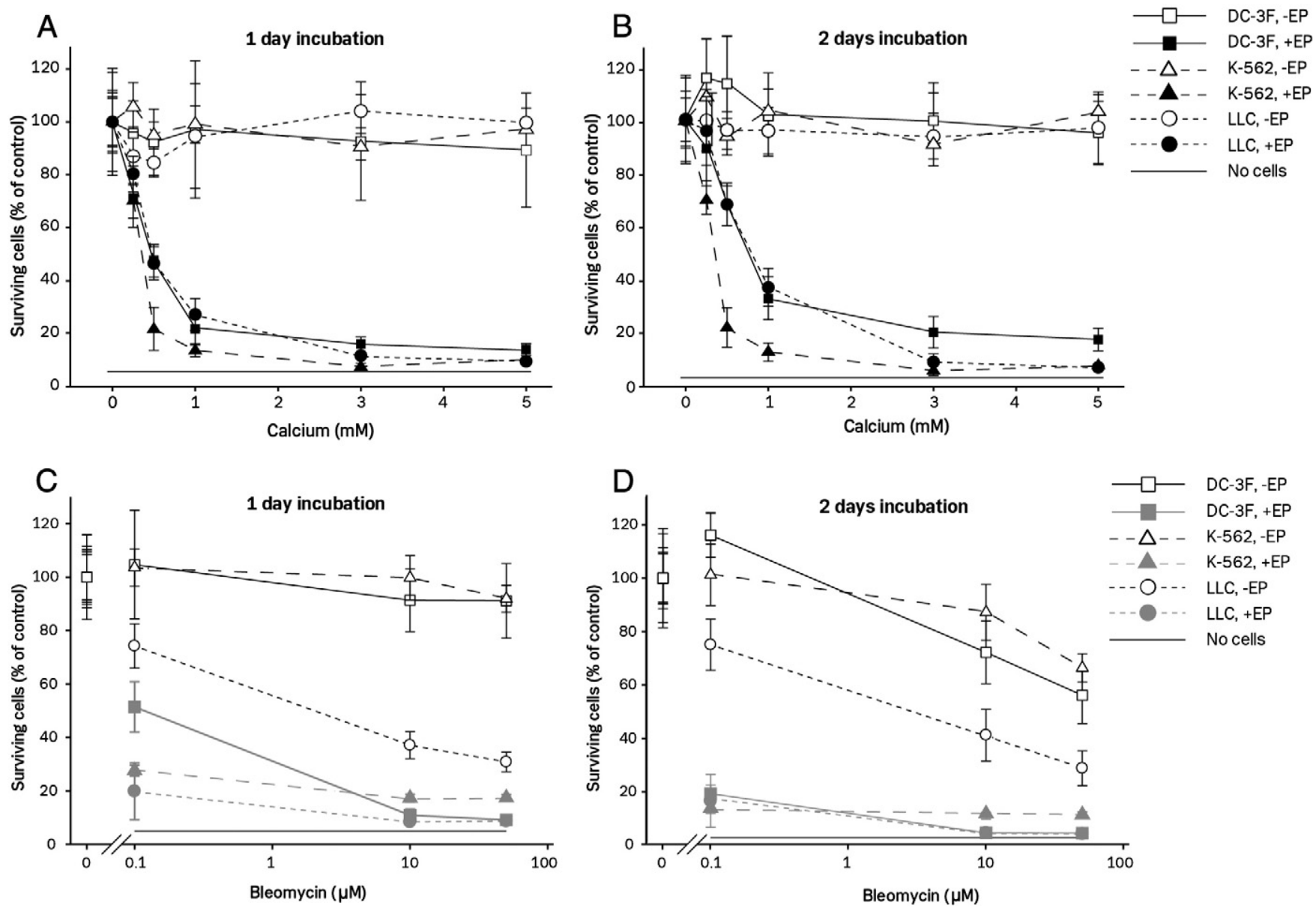

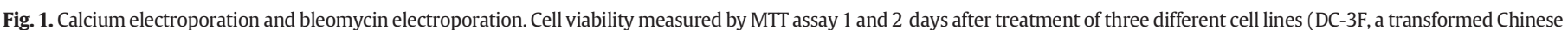

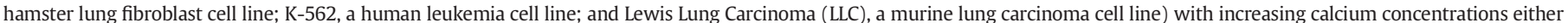

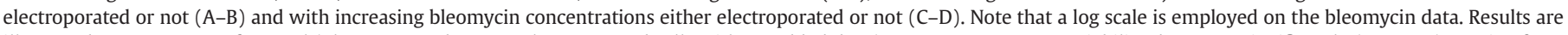

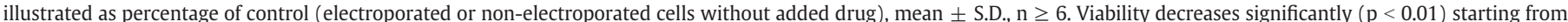

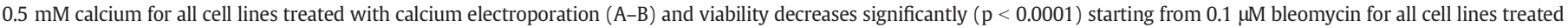
with bleomycin electroporation (C-D).

Panels A-B are reproduced from [17]. 
phosphate precipitate. Subsequently, $270 \mu \mathrm{l} 6.1 * 10^{6}$ cells $/ \mathrm{ml}$ (cooled cells-approximately $8{ }^{\circ} \mathrm{C}$ ) were electroporated in $4 \mathrm{~mm}$ cuvettes (Molecular BioProducts, Inc.) in the presence of $30 \mu \mathrm{l}$ bleomycin (0-50 $\mu \mathrm{M}$ final concentration; Baxter Oncology $\mathrm{GmbH}$ ), and/or calcium chloride (0-5 mM final concentration; prepared by SAD, Denmark), or calcium glubionate ( $1 \mathrm{mM}$ final concentration; Calcium Sandoz, Novartis), or HEPES (controls). Electroporation parameters for DC-3F and K-562 were as follows: 8 pulses of $99 \mu$ s with $1.2 \mathrm{kV} / \mathrm{cm}$ and $1 \mathrm{~Hz}$, and 8 pulses of $99 \mu$ s with $1.4 \mathrm{kV} / \mathrm{cm}$ and $1 \mathrm{~Hz}$ for Lewis Lung Carcinoma using a BTX T820 square wave electroporator (BTX Harvard Apparatus). Parameters for each cell line were optimized for high permeabilisation and low cellular death by electroporation alone. DC-3F cells were also electroporated at increasing electric field strength $(0-1.6 \mathrm{kV} / \mathrm{cm})$. After electroporation, cells incubated in $20 \mathrm{~min}$ at $37{ }^{\circ} \mathrm{C}$ and $5 \% \mathrm{CO}_{2}$ before being diluted in culture medium and being seeded in 96 -well plates $\left(3.1 * 10^{4}\right.$ cells $\left./ 100 \mu \mathrm{l}\right)$.

\subsection{Viability assay}

Viability of the cells following treatment, with or without electroporation in the presence of bleomycin and/or calcium chloride, or calcium glubionate, was measured using MTT (3-(4,5-Dimethylthiazol-2-yl)2,5-diphenyltetrazolium bromide) assay as described previously [20]. Briefly, cell viability was measured by MTT assay after 1 day (19-24 h) and/or 2 days (43-47 h) of incubation using MultiskanAscent ELISA reader (Thermo Labsystems).

\subsection{Statistical analyses}

Two-way ANOVA (Analysis of Variance) with post-hoc leastsquares-means test with Bonferroni correction was used to assess any differences between the groups. SAS 9.2 software (SAS Institute Inc.) was used for statistical analysis.

\section{Results and discussion}

\subsection{Comparison of the effect of calcium electroporation and bleomycin electroporation}

Three different cell lines were used to compare the effect of calcium electroporation and bleomycin electroporation in vitro. We have previously identified a dose-dependent decrease $(\mathrm{p}<0.0001)$ in the viability of all three cell lines treated with calcium electroporation, whereas no decrease in viability was seen in cells treated with calcium alone (Fig. 1A-B) [20]. Cells treated with bleomycin electroporation also showed a dose-dependent decrease in viability following treatment ( $p<0.0001$; Fig. 1C-D). The decrease in viability after treatment with calcium electroporation and bleomycin electroporation shows that similar effects can be achieved using these two treatment options. As expected, cells treated with bleomycin alone showed a significant decrease in viability (34-71\% two days after treatment with $50 \mu \mathrm{M}$ bleomycin, $\mathrm{p}<0.0001$ ) although not as dramatic as cells treated with bleomycin electroporation (89-96\% two days after treatment with bleomycin electroporation) (Fig. 1D). The decrease in viability after treatment with bleomycin alone is consistent with previous publications $[15,17,18]$. Due to the difference in viability between cells treated with bleomycin alone and calcium alone, one could speculate that calcium electroporation will cause fewer side effects on surrounding normal tissues than bleomycin electroporation using intratumoral injection. However, further studies are required to elucidate the effect of calcium electroporation on the surrounding normal tissue.

In the present study, we found that in vitro calcium electroporation using $1 \mathrm{mM}$ calcium induces a dramatic decrease in cell survival. Since

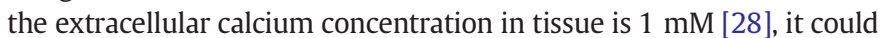
therefore be assumed that no additional calcium is required for calcium electroporation in tissue. Interestingly, research has shown that electroporation alone has a limited effect in the clinic [1,44], suggesting that the addition of calcium is required for calcium electroporation in tissue. We hypothesize that the in vivo $1 \mathrm{mM}$ calcium concentration reflects calcium, which may be bound to macromolecules, such as proteins. Therefore, much higher calcium concentration is required in vivo than in vitro. Furthermore, when injecting calcium intratumorally calcium will be diluted in plasma requiring injection of a higher calcium concentration than used in vitro.

\subsection{Effect of electroporation with calcium and bleomycin in combination}

In the present study, the effect of using sublethal doses of bleomycin and/or calcium together with electroporation was studied (Fig. 2). As shown in Fig. 2, cell survival decreased by $10-39 \%$ and by $40-52 \%$ after two days following treatment with calcium electroporation and bleomycin electroporation, respectively.

Treatment with calcium-bleomycin electroporation reduced survival by $51-67 \%$ in all three cell lines at the applied doses (Fig. 2). The decrease in survival after calcium-bleomycin electroporation seemed additive following 1 day incubation (data not shown), as well as following 2 days of incubation (Fig. 2). Further experiments are required to quantify the exact effects of the combined treatment. Bleomycin is a glycopeptidic antibiotic agent that cleaves DNA, resulting in singlestrand and double-strand breaks [45]. Therefore, calcium electroporation and bleomycin electroporation induce cellular death independently by principally different mechanisms, which in turn, could explain observed additive effect.

\subsection{Testing the effect of different calcium compounds and electric field strength}

The voltage dependency of bleomycin and calcium, as well as the importance of the calcium compound (calcium chloride and calcium glubionate) was tested 1 day after treatment using the DC-3F cell line (Fig. 3). The selected calcium and bleomycin concentrations (1 mM

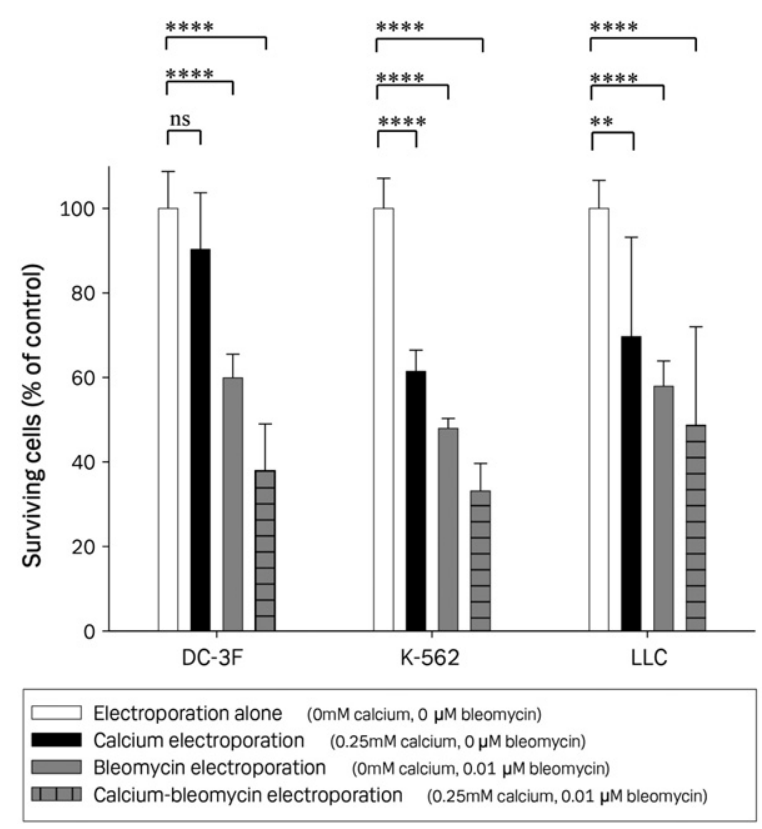

Fig. 2. Calcium-bleomycin electroporation. Cell viability measured by MTT assay 2 days after treatment of three different cell lines (DC-3F, a transformed Chinese hamster lung fibroblast cell line; K-562, a human leukemia cell line; and Lewis Lung Carcinoma (LLC), a murine lung carcinoma cell line) with electroporation alone, calcium electroporation, bleomycin electroporation, or calcium-bleomycin electroporation. Results are illustrated as percentage of control (electroporated alone), mean + S.D., $n=6$, ns $=$ not significant, ${ }^{* *}$ depicts $\mathrm{p}<0.01,{ }^{* * * *}$ depicts $\mathrm{p}<0.0001$. 
and $10 \mu \mathrm{M}$, respectively) were chosen as cell survival was below $25 \%$ at these concentrations 1 day post-electroporation (Fig. 1A and C).

Cell survival decreased with increasing voltages applied during electroporation with bleomycin or calcium. At $0 \mathrm{kV} / \mathrm{cm}$ (no electroporation), cell viability was 23-26\% lower following bleomycin treatment when compared to calcium treatment (Fig. 3A). Therefore, a direct comparison was not possible without adjusting for the percentage of viable cells at $0 \mathrm{kV} / \mathrm{cm}$. In Fig. 3B, this adjustment was performed. This analysis revealed that the effect of the applied voltage is similar in the calcium and bleomycin electroporation treatment groups, suggesting that a similar ratio of applied voltage to electrode distance $(\mathrm{kV} / \mathrm{cm})$ should be used for calcium electroporation and for bleomycin electroporation.

To test whether different calcium compounds had similar effects on cell survival following electroporation, calcium chloride or calcium glubionate was applied in electroporation. As seen in Fig. 3, no statistical significant difference $(\mathrm{p}=1.00)$ in the effect of calcium electroporation using calcium chloride or calcium glubionate was observed when compared on a molar level of calcium.

This finding suggests that both clinically available calcium compounds can be used for calcium electroporation. Interestingly, this experiment also revealed no change in viability after treatment with calcium alone, unlike after treatment with bleomycin alone (Fig. 3A), indicating a lower toxicity of calcium to non-electroporated cells.
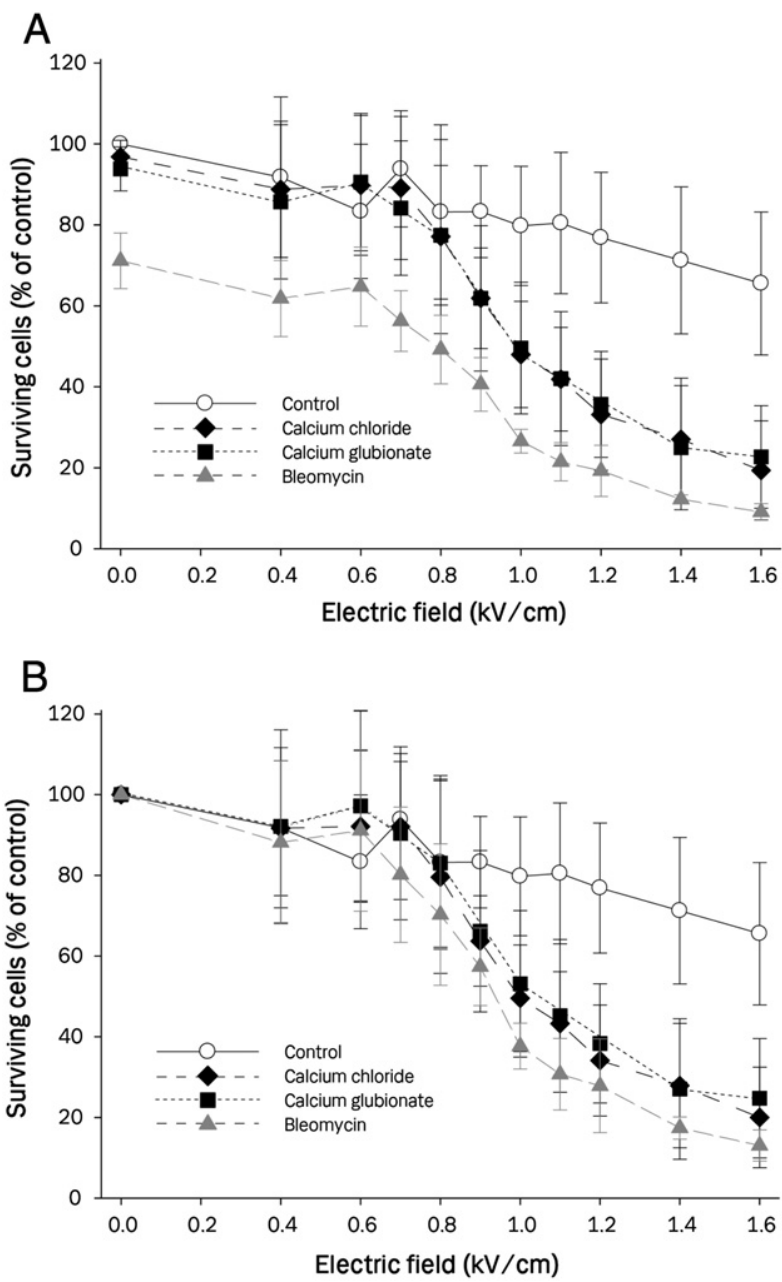

Fig. 3. Calcium sources and electric field condition. Cell viability measured by MTT assay 1 day after treatment of DC-3F cells (a transformed Chinese hamster lung fibroblast cell line) with electroporation alone, calcium electroporation using either $1 \mathrm{mM}$ calcium chloride or $1 \mathrm{mM}$ calcium glubionate as calcium source, or bleomycin electroporation (10 $\mu \mathrm{M}$ bleomycin). All electroporated at increasing ratio of applied voltage to electrode distance. Results are illustrated as percentage of control of $(A)$ non-electroporated cells with no drug or (B) non-electroporated cells with drug, mean \pm S.D., $\mathrm{n}=6$.
As only cell survival was tested, and not calcium influx, we were unable to conclude whether calcium influx happens at lower voltages. If calcium influx occurs at voltages below $0.8 \mathrm{kV} / \mathrm{cm}$, the cells appear to be able to re-establish ion homeostasis, reflected by cell survival rates similar to untreated cells (Fig. 3 ).

\section{Conclusions}

Calcium electroporation has previously been shown as an effective anti-cancer treatment. The current study addressed several central questions that will arise during the planning of clinical or veterinary trials. Calcium electroporation is equally as potent as bleomycin electroporation in inducing cellular death. Based on in vitro experiments, it became evident that similar electric field strengths should be applied when using calcium or bleomycin in electroporation-based therapy. This finding facilitates future clinical calcium electroporation testing, as the electric field strengths used in bleomycin electroporation are the parameters commonly used in clinical practice [3].

Finally, the effect of calcium electroporation was independent of calcium compound (calcium chloride or calcium glubionate) when compared on a molar level. Therefore, both clinically available calcium compounds can be applied in calcium electroporation.

\section{Contribution}

S.K. Frandsen, H. Gissel, P. Hojman, J. Eriksen and J. Gehl designed the study. All authors wrote the manuscript. S.K. Frandsen carried out all the experiments.

\section{Financial support}

S.K. Frandsen was supported by a scholarship from Danish Cancer Society and by a grant from Technical University of Denmark, P. Hojman is supported by a grant from Danish Medical Research Council and Copenhagen University Hospital, H. Gissel is supported by a grant from the Lundbeck Foundation, and J. Gehl is a research fellow of the Royal Swedish Academy of Sciences supported by the Acta Oncologica Foundation.

\section{Conflicts of interest}

A patent has been submitted (inventors S.K. Frandsen, H. Gissel, P. Hojman, J. Eriksen, and J. Gehl).

\section{Acknowledgements}

The authors thank Marianne Fregil for providing excellent technical assistance.

\section{References}

[1] M. Belehradek, C. Domenge, B. Luboinski, S. Orlowski, J. Belehradek Jr., L.M. Mir, Electrochemotherapy, a new antitumor treatment. First clinical phase I-II trial, Cancer 72 (1993) 3694-3700.

[2] R. Heller, M.J. Jaroszeski, D.S. Reintgen, C.A. Puleo, R.C. DeConti, R.A. Gilbert, L.F. Glass, Treatment of cutaneous and subcutaneous tumors with electrochemotherapy using intralesional bleomycin, Cancer 83 (1998) 148-157.

[3] M. Marty, G. Sersa, J.R. Garbay, J. Gehl, C.G. Collins, M. Snoj, V. Billard, P.F. Geertsen, J.O. Larkin, D. Miklavcic, I. Pavlovic, S.M. Paulin-Kosir, M. Cemazar, N. Morsli, Z. Rudolf, C. Robert, G.C. O'Sullivan, L.M. Mir, Electrochemotherapy-an easy, highly effective and safe treatment of cutaneous and subcutaneous metastases: results of ESOPE (European Standard Operating Procedures of Electrochemotherapy) study, EJC Suppl. 4 (2006) 3-13.

[4] P. Quaglino, C. Mortera, S. Osella-Abate, M. Barberis, M. Illengo, M. Rissone, P. Savoia, M.G. Bernengo, Electrochemotherapy with intravenous bleomycin in the local treatment of skin melanoma metastases, Ann. Surg. Oncol. 15 (2008) 2215-2222.

[5] A. Testori, P. Rutkowski, J. Marsden, L. Bastholt, V. Chiarion-Sileni, A. Hauschild, A.M. Eggermont, Surgery and radiotherapy in the treatment of cutaneous melanoma, Ann. Oncol. 20 (Suppl. 6) (2009) vi22-vi29. 
[6] L.W. Matthiessen, R.L. Chalmers, D.C. Sainsbury, S. Veeramani, G. Kessell, A.C. Humphreys, J.E. Bond, T. Muir, J. Gehl, Management of cutaneous metastases using electrochemotherapy, Acta Oncol. 50 (2011) 621-629.

[7] I. Edhemovic, E.M. Gadzijev, E. Brecelj, D. Miklavcic, B. Kos, A. Zupanic, B. Mali, T. Jarm, D. Pavliha, M. Marcan, G. Gasljevic, V. Gorjup, M. Music, T.P. Vavpotic, M. Cemazar, M. Snoj, G. Sersa, Electrochemotherapy: a new technological approach in treatment of metastases in the liver, Technol. Cancer Res. Treat. 10 (2011) 475-485.

[8] L.G. Campana, S. Valpione, S. Mocellin, R. Sundararajan, E. Granziera, L. Sartore, V. Chiarion-Sileni, C.R. Rossi, Electrochemotherapy for disseminated superficial metastases from malignant melanoma, Br. J. Surg. 99 (2012) 821-830.

[9] P. Curatolo, P. Quaglino, F. Marenco, M. Mancini, T. Nardo, C. Mortera, R. Rotunno, S. Calvieri, M.G. Bernengo, Electrochemotherapy in the treatment of Kaposi sarcoma cutaneous lesions: a two-center prospective phase II trial, Ann. Surg. Oncol. 19 (2012) 192-198.

[10] L.W. Matthiessen, H.H. Johannesen, H.W. Hendel, T. Moss, C. Kamby, J. Gehl, Electrochemotherapy for large cutaneous recurrence of breast cancer: a phase II clinical trial, Acta Oncol. 51 (2012) 713-721.

[11] G. Sersa, T. Cufer, S.M. Paulin, M. Cemazar, M. Snoj, Electrochemotherapy of chest wall breast cancer recurrence, Cancer Treat. Rev. 38 (2012) 379-386.

[12] E.P. Spugnini, F. Baldi, P. Mellone, F. Feroce, A. D'Avino, F. Bonetto, B. Vincenzi, G. Citro, A. Baldi, Patterns of tumor response in canine and feline cancer patients treated with electrochemotherapy: preclinical data for the standardization of this treatment in pets and humans, J. Transl. Med. 5 (2007) 48.

[13] M. Cemazar, Y. Tamzali, G. Sersa, N. Tozon, L.M. Mir, D. Miklavcic, R. Lowe, J. Teissie, Electrochemotherapy in veterinary oncology, J. Vet. Intern. Med. 22 (2008) 826-831.

[14] Y. Tamzali, L. Borde, M.P. Rols, M. Golzio, F. Lyazrhi, J. Teissie, Successful treatment of equine sarcoids with cisplatin electrochemotherapy: a retrospective study of 48 cases, Equine Vet. J. 44 (2012) 214-220.

[15] S. Orlowski, J. Belehradek Jr., C. Paoletti, L.M. Mir, Transient electropermeabilization of cells in culture. Increase of the cytotoxicity of anticancer drugs, Biochem. Pharmacol. 37 (1988) 4727-4733.

[16] G. Sersa, M. Cemazar, D. Miklavcic, Antitumor effectiveness of electrochemotherapy with cis-diamminedichloroplatinum(II) in mice, Cancer Res. 55 (1995) 3450-3455.

[17] J. Gehl, T. Skovsgaard, L.M. Mir, Enhancement of cytotoxicity by electropermeabilization: an improved method for screening drugs, Anti-Cancer Drugs 9 (1998)319-325.

[18] M.J. Jaroszeski, V. Dang, C. Pottinger, J. Hickey, R. Gilbert, R. Heller, Toxicity of anticancer agents mediated by electroporation in vitro, Anti-Cancer Drugs 11 (2000) 201-208.

[19] J.L. Vasquez, J. Gehl, G.G. Hermann, Electroporation enhances mitomycin C cytotoxicity on T24 bladder cancer cell line: a potential improvement of intravesical chemotherapy in bladder cancer, Bioelectrochemistry 88 (2012) 127-133.

[20] S.K. Frandsen, H. Gissel, P. Hojman, T. Tramm, J. Eriksen, J. Gehl, Direct therapeutic applications of calcium electroporation to effectively induce tumor necrosis, Cancer Res. 72 (2012) 1336-1341.

[21] A. Bergner, R.M. Huber, Regulation of the endoplasmic reticulum $\mathrm{Ca}^{2+}-$ store in cancer, Anti Cancer Agents Med. Chem. 8 (2008) 705-709.

[22] A.M. Florea, D. Busselberg, Anti-cancer drugs interfere with intracellular calcium signaling, Neurotoxicology 30 (2009) 803-810.

[23] E. Carafoli, L. Santella, D. Branca, M. Brini, Generation, control, and processing of cellular calcium signals, Crit. Rev. Biochem. Mol. Biol. 36 (2001) 107-260.

[24] M.J. Berridge, M.D. Bootman, H.L. Roderick, Calcium signalling: dynamics, homeostasis and remodelling, Nat. Rev. Mol. Cell Biol. 4 (2003) 517-529.

[25] C. Giorgi, A. Romagnoli, P. Pinton, R. Rizzuto, $\mathrm{Ca}^{2+}$ signaling, mitochondria and cell death, Curr. Mol. Med. 8 (2008) 119-130.

[26] C. Cerella, M. Diederich, L. Ghibelli, The dual role of calcium as messenger and stressor in cell damage, death, and survival, Int. J. Cell Biol. 2010 (2010) 546163.
[27] B. Zhivotovsky, S. Orrenius, Calcium and cell death mechanisms: a perspective from the cell death community, Cell Calcium 50 (2011) 211-221.

[28] M. Brini, E. Carafoli, Calcium signalling: a historical account, recent developments and future perspectives, Cell. Mol. Life Sci. 57 (2000) 354-370.

[29] P.A. Garcia, T. Pancotto, J.H. Rossmeisl Jr., N. Henao-Guerrero, N.R. Gustafson, G.B. Daniel, J.L. Robertson, T.L. Ellis, R.V. Davalos, Non-thermal irreversible electroporation (N-TIRE) and adjuvant fractionated radiotherapeutic multimodal therapy for intracranial malignant glioma in a canine patient, Technol. Cancer Res. Treat. 10 (2011) 73-83.

[30] I. Semenov, S. Xiao, A.G. Pakhomov, Primary pathways of intracellular $\mathrm{Ca}(2+)$ mobilization by nanosecond pulsed electric field, Biochim. Biophys. Acta 1828 (2013) 981-989.

[31] P.T. Vernier, Y. Sun, M.T. Chen, M.A. Gundersen, G.L. Craviso, Nanosecond electric pulse-induced calcium entry into chromaffin cells, Bioelectrochemistry 73 (2008) $1-4$.

[32] S.J. Beebe, X. Chen, J.A. Liu, K.H. Schoenbach, Nanosecond pulsed electric field ablation of hepatocellular carcinoma, Conf. Proc. IEEE Eng. Med. Biol. Soc. 2011 (2011) 6861-6865.

[33] R. Nuccitelli, K. Tran, B. Athos, M. Kreis, P. Nuccitelli, K.S. Chang, E.H. Epstein Jr., J.Y. Tang, Nanoelectroablation therapy for murine basal cell carcinoma, Biochem. Biophys. Res. Commun. 424 (2012) 446-450.

[34] H. Aihara, J. Miyazaki, Gene transfer into muscle by electroporation in vivo, Nat. Biotechnol. 16 (1998) 867-870.

[35] I. Spanggaard, M. Snoj, A. Cavalcanti, C. Bouquet, G. Sersa, C. Robert, B. Vasseur, P. Attali, L. Mir, J. Gehl, Proof of concept of gene therapy using plasmid AMEP in disseminated melanoma: safety and efficacy results of a phase I first-in-man study, Ann. Oncol. 23 (2012).

[36] L.M. Mir, M.F. Bureau, J. Gehl, R. Rangara, D. Rouy, J.M. Caillaud, P. Delaere, D Branellec, B. Schwartz, D. Scherman, High-efficiency gene transfer into skeletal muscle mediated by electric pulses, Proc. Natl. Acad. Sci. U. S. A. 96 (1999) 4262-4267.

[37] P. Hojman, H. Gissel, J. Gehl, Sensitive and precise regulation of haemoglobin after gene transfer of erythropoietin to muscle tissue using electroporation, Gene Ther. 14 (2007) 950-959.

[38] A.I. Daud, R.C. DeConti, S. Andrews, P. Urbas, A.I. Riker, V.K. Sondak, P.N. Munster D.M. Sullivan, K.E. Ugen, J.L. Messina, R. Heller, Phase I trial of interleukin-12 plasmid electroporation in patients with metastatic melanoma, J. Clin. Oncol. 26 (2008) 5896-5903.

[39] A. Gothelf, P. Hojman, J. Gehl, Therapeutic levels of erythropoietin (EPO) achieved after gene electrotransfer to skin in mice, Gene Ther. 17 (2010) 1077-1084

[40] D. Pavlin, M. Cemazar, G. Sersa, N. Tozon, IL-12 based gene therapy in veterinary medicine, J. Transl. Med. 10 (2012) 234.

[41] R. Draghia-Akli, K.A. Hahn, G.K. King, K.K. Cummings, R.H. Carpenter, Effects of plasmid-mediated growth hormone-releasing hormone in severely debilitated dogs with cancer, Mol. Ther. 6 (2002) 830-836.

[42] J. Cutrera, M. Torrero, K. Shiomitsu, N. Mauldin, S. Li, Intratumoral bleomycin and IL-12 electrochemogenetherapy for treating head and neck tumors in dogs, Methods Mol. Biol. 423 (2008) 319-325.

[43] P. Hojman, I. Spanggaard, C.H. Olsen, J. Gehl, H. Gissel, Calcium electrotransfer for termination of transgene expression in muscle, Hum. Gene Ther. 22 (2011) 753-760.

[44] L.F. Glass, M.L. Pepine, N.A. Fenske, M. Jaroszeski, D.S. Reintgen, R. Heller, Bleomycin-mediated electrochemotherapy of metastatic melanoma, Arch. Dermatol. 132 (1996) 1353-1357.

[45] L.M. Mir, O. Tounekti, S. Orlowski, Bleomycin: revival of an old drug, Gen. Pharmacol. 27 (1996) 745-748. 